Pacific Northwest

National Laboratory

Operated by Battelle for the

U.S. Department of Energy

\section{FY 2000 Buildings Energy Savings Estimates Under Uncertainty: Developing Approaches for Incorporating Risk into Buildings Program Energy Efficiency Estimates}

D. M. Anderson

November 2002

Prepared for the U.S. Department of Energy under Contract DE-AC06-76RL01830 


\title{
DISCLAIMER
}

This report was prepared as an account of work sponsored by an agency of the United States Government. Neither the United States Government nor any agency thereof, nor Battelle Memorial Institute, nor any of their employees, makes any warranty, express or implied, or assumes any legal liability or responsibility for the accuracy, completeness, or usefulness of any information, apparatus, product, or process disclosed, or represents that its use would not infringe privately owned rights. Reference herein to any specific commercial product, process, or service by trade name, trademark, manufacturer, or otherwise does not necessarily constitute or imply its endorsement, recommendation, or favoring by the United States Government or any agency thereof, or Battelle Memorial Institute. The views and opinions of authors expressed herein do not necessarily state or reflect those of the United States Government or any agency thereof.

\author{
PACIFIC NORTHWEST NATIONAL LABORATORY \\ operated by \\ BATTELLE \\ for the
}

UNITED STATES DEPARTMENT OF ENERGY

under Contract DE-AC06-76RLO 1830

Printed in the United States of America

Available to DOE and DOE contractors from the

Office of Scientific and Technical Information, P.O. Box 62, Oak Ridge, TN 37831;

prices available from (615) 576-8401.

Available to the public from the National Technical Information Service,

U.S. Department of Commerce, 5285 Port Royal Rd., Springfield, VA 22161

This document was printed on recycled paper. 


\section{FY2000 Buildings Energy Savings Estimates Under Uncertainty: Developing Approaches for Incorporating Risk into Buildings Program Energy Efficiency Estimates}

D.M. Anderson

November 2002

Prepared for

the U.S. Department of Energy

under Contract DE-AC06-76RL01830

Pacific Northwest National Laboratory

Richland, Washington 99352 



\section{Preface}

This report was prepared at the request of Jerry Dion, Senior Program Analyst in the Office of Policy, Budget Formulation and Analysis (PBFA). PBFA is one office within the Office of Energy Efficiency and Renewable Energy (EERE) at the U.S. Department of Energy (DOE). This report is one of two that re-examines the forecasted impact of individual programs currently within the Buildings Technology Program (BT) and the Weatherization and Intergovernmental Program (WIP) that appeared in the FY2000 Presidential Budget request. This report develops potential methods for allowing inherent risk to be captured in the program benefits analysis. Note that the FY2000 budget request was originally analyzed under the former Office of Building Technology, State and Community Programs (BTS), where BT and WIP were previously combined. Throughout the document, reference will be made to the predecessor of the BT and WIP programs, BTS, as FY2000 reflected that organization.

A companion report outlines the effects of re-estimating the FY2000 budget request based on overlaying program data from subsequent years - essentially revised out-year forecasts. That report shows that yearto-year long-term projections of primary energy savings can vary widely as models improve and programs change. Those point estimates are not influenced by uncertainty or risk. This report develops potential methods for allowing inherent risk to affect the benefits analysis via Monte Carlo simulation. 


\section{Summary}

The Government Performance and Results Act requires, in part, that government agencies provide an estimate of the impact of the programs for which funds are requested in the President's annual budget request. The current benefits analysis process, as conducted within the Office of Energy Efficiency and Renewable Energy (EERE) at the US Department of Energy (DOE) assumes 100 percent success in all aspects of the proposed program. Even though this is part of the Office of Management and Budget (OMB) guidance, we know that this is a very optimistic assumption, particularly as regards R\&D. If we incorporate risk through simulation, the estimated impacts are shown to shrink significantly, depending upon the level of assumed risk. This report asserts that risk governs the success of EERE portfolio, just as in other aspects of forecasting, and that risk should be considered explicitly as part of any portfolio management process.

Currently, EERE uses deterministic models or other analytical approaches to generate point estimates of forecasted annual energy savings and other benefits deriving from successful implementation of the various programs managed by that office. PNNL, on behalf of the Building Technology (BT) and Weatherization and Intergovernmental Programs (WIP) provides such estimates for programs focused on the buildings marketplace. By definition, point estimates are calculations devoid of explicit statistical significance. That is, they contain no information about certainty, or uncertainty, associated with the likelihood that the point represents "the" number. When that number is a projection of energy savings 10 , 20 , and even 30 years into the future, the likelihood that the savings will be equal to precisely "that" number is unlikely.

Risk was applied to the BT/WIP portfolio energy savings point estimates in two ways. One approach included applying hypothetical probability distributions to the point estimates produced by the deterministic models. This is equivalent to providing error bands to the deterministic estimates. The other approach introduced and propagated uncertainty by assigning a probability distribution to each program's year-to-year energy savings growth rate that is implied by the deterministic models' point estimates (the growth that must take place to reach each successive level of savings in each out-year). Both approaches relied on assigning assumed levels of risk (low, medium, high) to each individual program modeled in the portfolio. These probability distributions reflect reasonable, though subjective, assumptions about portfolio success. Simple Monte Carlo simulation was used to populate the distribution of results under various scenarios. Averaging among the results of these distributions gives an indication of what the energy savings would be under an assumed range of year-to-year program success.

For example, the results in Table S1 resulted from applying assumed program risk levels of low (95 percent average probability of success with a standard deviation of 5 percent), medium ( 80 percent average probability of success with a standard deviation of 20 percent), and high (50 percent average probability of success with a standard deviation of 40 percent). 
Table S1. Effects on 2020 portfolio energy savings estimates of alternative approaches ${ }^{(a)}$ to applying risk.

\begin{tabular}{|l|c|c|}
\hline \multicolumn{1}{|c|}{ Approach } & $\begin{array}{c}\text { Average 2020 Energy } \\
\text { Savings (TBtu) }\end{array}$ & $\begin{array}{c}\text { Standard } \\
\text { Deviation }\end{array}$ \\
\hline Original FY2000 Deterministic Point Estimate & 4,447 & 0.0 \\
\hline Risk Bands Applied to Annual Estimates & 3,218 & 271.1 \\
\hline Risk Propagated through Annual Growth Rates & 1,215 & 86.5 \\
\hline (a) These results reflect just one of 16 alternative risk scenarios that were each modeled in a 20,000-iteration Monte Carlo simulation. \\
\hline
\end{tabular}

Incorporating some level of risk to portfolio success results in significant decreases in estimated energy savings, depending on the level of risk assumed. This indicates that risk is important to consider, as it has a major impact on outcome (forecasted energy savings). This paper demonstrates that is it possible to capture, measure, and assess risk. It also points out that improving the assessment of risk by tightening the probability distributions associated with program outcomes is essential. Future planning efforts and portfolio assessments should make an effort to capture and analyze risk given this impact. 


\section{Contents}

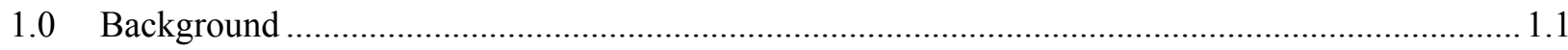

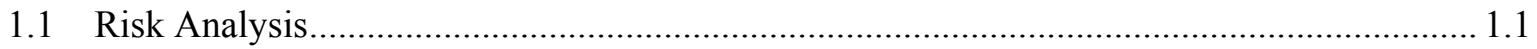

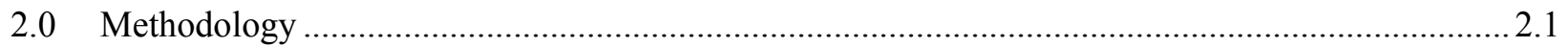

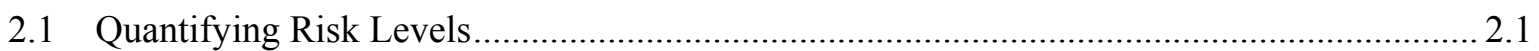

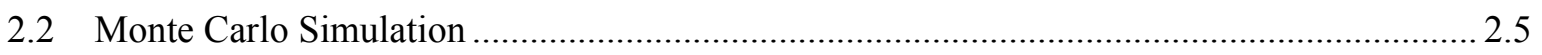

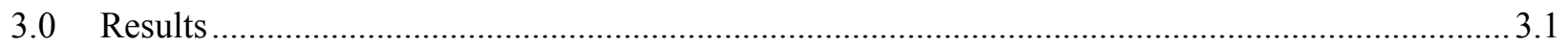

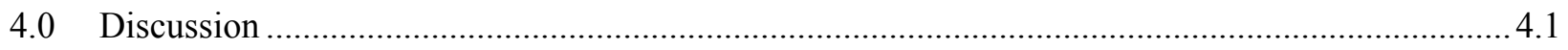

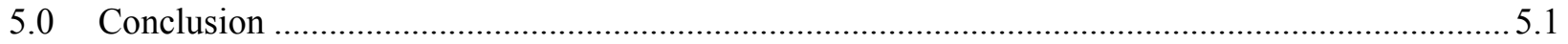

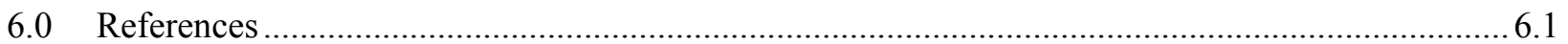




\section{Figures}

2.1. Normal Distribution

2.2. Actual Examples of Alternative Savings Trajectories Represented in the Risk Propagation Approach

2.3. Example: Implied Annual Growth Rate Over Time for One Simulation Iteration ......................... 2.6

2.4. Example: Savings Streams from the Alternative Approaches for One Simulation Iteration ............ 2.6

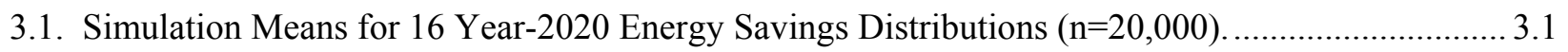

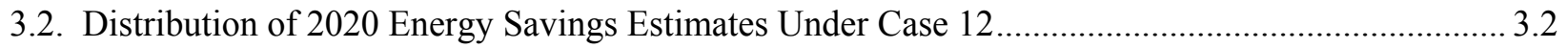

\section{Tables}

2.1. Assumed Risk Levels of Individual Programs in the FY2000 BTS Portfolio

2.2. Probability Scenarios Used to Simulate Risk Levels

3.1. Estimated 2020 Portfolio Primary Energy Savings (TBtu) Distribution Statistics for the 16 Simulation Cases $(n=20,000)$ 


\subsection{Background}

The information generated by the EERE benefits estimates effort is used to meet the Government Performance and Results Act of 1993 (GPRA) requirements for DOE, which include the development of a Strategic Plan and, eventually, the development of Annual Performance Reports and Annual Performance Plans. The EERE GPRA Metrics effort is a systematic process to estimate the benefits of EERE's programs and technologies, and to relate the benefits to Departmental and EERE strategic goals and objectives. BTS (predecessor to the current Buildings Technology and Weatherization/Intergovernmental programs) used the EERE GPRA process for the FY2000 Budget Request to develop and validate the Strategic Plan goal of saving 2 quadrillion BTUs (quads) of energy per year by 2010, rising to 5 quads per year by 2020 .

Each year, EERE's Office of Planning, Budget Formulation and Analysis (PBFA) issues guidance to assist the programs and offices with the development of these estimates. That guidance explicitly requires that individual programs assume 100 percent success of their program goals and full budget funding at requested levels when developing benefits estimates for a planning horizon of 20-30 years. This requirement disallows the incorporation of risk, and results in single point estimates for projected savings in each out year.

\subsection{Risk Analysis}

Sometimes our efforts are met with complete success and sometimes not. Often, the end result lies somewhere in the middle. This is as true for government programs as for anything else. It is important to make some estimate of the probability of success (or failure) in order to adequately plan and to assist resource decisions.

Risks vary widely across programs, depending on the developmental stage of the program strategy. Research and Development, Codes and Standards, and Implementation and Deployment programs all have different types of risk characteristics. Even risk itself can be further categorized by technical and market risk, and in the case of government programs, political risk.

For instance, $R \& D$ programs may have a high technical risk depending upon the stage of development. As the product (or program) nears commercialization, market risk begins to dominate. Political risk comes into play as a risk to continued funding or support for program goals. One example of political risk might be the level at which a standard is issued when such a standard is developed in a consensus process, rather than based purely upon technical and economic considerations.

Pure research programs that are attempting to derive operational technologies from theory face tremendous risk when we try to estimate potential energy savings in the GPRA framework. Such programs do not yet have a "widget" to test and measure savings potential. They have yet to face any of the downstream risks to new technologies, such as production constraints, partner recruitment, and market acceptance. Other programs, such as Energy Star and the Lighting Collaborative (CFL), have already traveled the development road and are in the process of being accepted by the market. Most of the risk in these programs has already been removed, and they are producing energy savings. The principal remaining risk is what the market penetration path will be. Yet another form of risk is introduced to programs 
like Weatherization Assistance or State Energy Program by their measurement algorithms. Such programs rely on calculations of assumed energy savings per home weatherized or per dollar granted. In these cases, because of the variability in actual on-the-ground application, there is uncertainty in whether the savings actually being achieved conform to the average used in modeling the benefits. 


\subsection{Methodology}

In this framework, risk was not differentiated by type (technical, market, or political) or strategy (R\&D, Codes and Standards, or Implementation and Deployment). For simplicity sake, individual programs were assumed to have either low, medium, or high risk associated with their long-term success. Following the logic that risk increases the further from market that a program is on the development continuum, programs like Energy Star, CFLs, and various equipment standards were assumed to have low risk relative to research programs like Appliances and Emerging Technologies R\&D. Such research programs were assumed to have high risk. Medium risk was assigned to programs, such as Design Tools and Strategies and State Grants, in part to reflect their measurement risk. The State Energy Program relies on energy savings estimates based on a savings-per-budget-dollar-granted approach. However, little or no accounting for the savings has been conducted to benchmark that algorithm, as the states are generally free to determine the use of the funds. Table 2.1 outlines the levels of risk subjectively assumed to apply to each program modeled for FY2000.

Assigning assumed risk levels to individual programs cuts both ways. Programs assigned a risk level of "high" can have outcomes that vary widely. A research program may develop a revolutionary new technology that may greatly exceed all estimates of energy savings that we currently project for the research program today. Or, it may never pan out and hence never result in any savings. Programs having low risk or medium risk will probably result in some level of energy savings. Analysts and program managers have good knowledge of what those expected savings levels are likely to be through time. Therefore, probability distributions affecting the estimates are relatively tighter for the low- or medium-risk programs than for programs having higher risk levels.

Note that a nearly endless number of scenarios could be modeled based on reassigning program risk levels in various alternative combinations to those presented in Table 2.1. The point of this paper is to demonstrate the application of risk, not to flesh out all the potential scenarios of risk that might apply to the buildings portfolio. Therefore, the levels in the table were held constant, while the definitions of low, medium, and high were allowed to vary across 16 arbitrary scenarios.

\subsection{Quantifying Risk Levels}

Currently, PNNL uses an analytical framework based on both internally and externally developed models (Belzer et al., 2002). These deterministic models produce annual point estimates of primary energy savings, among many other measures of program benefits. As a result of having annual point estimates, year-over-year portfolio energy savings growth factors also can be implied for the 2000-2020 period. These annual estimates and their accompanying annual growth factors form the basis to which the risk levels in Table 2.1 were applied. 
Table 2.1. Assumed Risk Levels of Individual Programs in the FY2000 BTS Portfolio

\begin{tabular}{|c|c|}
\hline FY 2000 BTS Program & $\begin{array}{c}\text { Assumed Risk } \\
\text { Level }\end{array}$ \\
\hline State Formula Grants & Medium \\
\hline Weatherization Assistance & Low \\
\hline Rebuild America & Low \\
\hline Training \& Assistance for Codes & Low \\
\hline Energy Star: Clothes Washers & Low \\
\hline Energy Star: Refrigerators & Low \\
\hline Energy Star: Electric Water Heaters & Low \\
\hline Technology Roadmaps \& Competitive R\&D & High \\
\hline Residential Buildings Research and Development & High \\
\hline Residential Building Codes & Low \\
\hline Commercial Buildings Research and Development & High \\
\hline Commercial Building Codes & Low \\
\hline Lighting Applications and Impacts & Medium \\
\hline Lighting Collaborative (CFL) & Low \\
\hline Adv. Light Sources, Electronics, and New Concepts (LPSL) & High \\
\hline Building Envelope R\&D: Windows & High \\
\hline Building Envelope R\&D: Roofs and Insulation & High \\
\hline Building Envelope R\&D: Reflective Surfaces & High \\
\hline Design Tools and Strategies & Medium \\
\hline Lighting \& Appliance Standards: Ballasts & Low \\
\hline Lighting \& Appliance Standards: Clothes Washers & Low \\
\hline Lighting \& Appliance Standards: Gas Water Heaters & Low \\
\hline Lighting \& Appliance Standards: Oil Water Heaters & Low \\
\hline Lighting \& Appliance Standards: Central Air Conditioners & Low \\
\hline Lighting \& Appliance Standards: Gas Furnaces & Low \\
\hline Lighting \& Appliance Standards: Oil Furnaces & Low \\
\hline Lighting \& Appliance Standards: Electric Water Heaters & Low \\
\hline Lighting \& Appliance Standards: Dist. Transformers & Low \\
\hline Appliances and Emerging Technologies R\&D & High \\
\hline Space Conditioning R\&D: Refrigeration & High \\
\hline
\end{tabular}


Risk levels were applied in two ways. The "risk band" approach relied on subjecting the 2020 point estimate of primary energy savings for each program to 16 alternative probability distributions chosen based on the risk level assigned to each program. The sum of these results across programs was taken as the portfolio-level result with assumed risk incorporated. Such an approach treats each year's deterministic estimate as independent from any other year, and implies that savings achieved in one year are not necessarily bound to savings estimated in previous years.

Risk levels were applied as the probability of program success, with a value of 1 meaning that the program would achieve the 2020 result determined by the FY2000 GPRA deterministic analysis. That probability was assumed to be normally distributed. For example, if we say that the Energy Star Refrigerators program has a low risk level, we could arbitrarily assign it a probability of success that is a normal distribution with a mean of 100 percent chance of success, and a standard deviation of, say, 5 percent. This means that 95 percent of the distribution of potential program success is within the $100 \% \pm 10 \%$ band. Figure 2.1 illustrates the properties of the normal distribution.

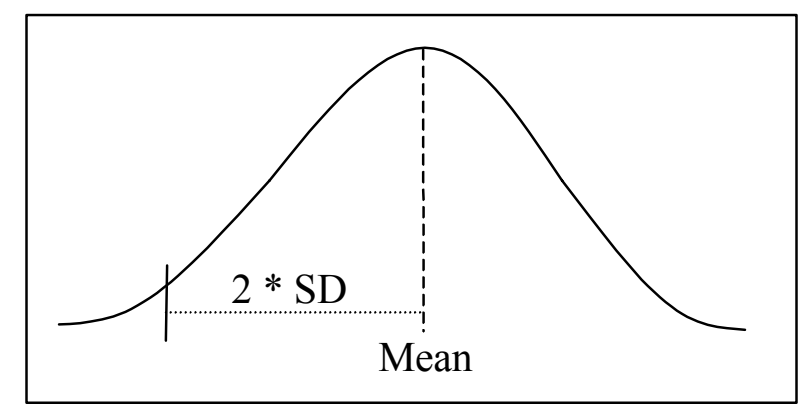

Figure 2.1. Normal Distribution

The "risk propagation" approach subjects the estimates to year-to-year dependency. The risk propagation approach applied the 16 alternative probability distributions to the annual growth factor of each program based on the assigned risk level. To propagate risk over the analysis period, each annual growth factor from the deterministic approach was multiplied by a probability of success in achieving that year's growth. Note that the resulting factor was constrained to not result in lost energy savings from year to year. This means that annual energy savings estimates do not decline compared to a previous year-once achieved, the savings lock-in. The estimated factor was then multiplied by the previous year's energy savings to provide the savings estimate for the current year. In this way, each succeeding year becomes subject to the results achieved in the previous year.

For example, if a program's growth estimate greatly exceeded original estimates in year 3 of a 20 -year period, that program's trajectory is elevated to a new level that becomes the baseline for the next year's estimation - effectively raising the 2020 potential savings. In other words, earlier, greater success leads to successively higher success levels in the future. By the same approach, a significant lack of growth in energy savings in year 3 would translate to a lower trajectory, setting a new lower baseline for all future estimates. This is analogous to the compounding interest problem. Figure 2.2 illustrates these properties. Any significant variances from the original deterministic baseline growth rates greatly affect the energy savings estimates achieved in 2020 . 


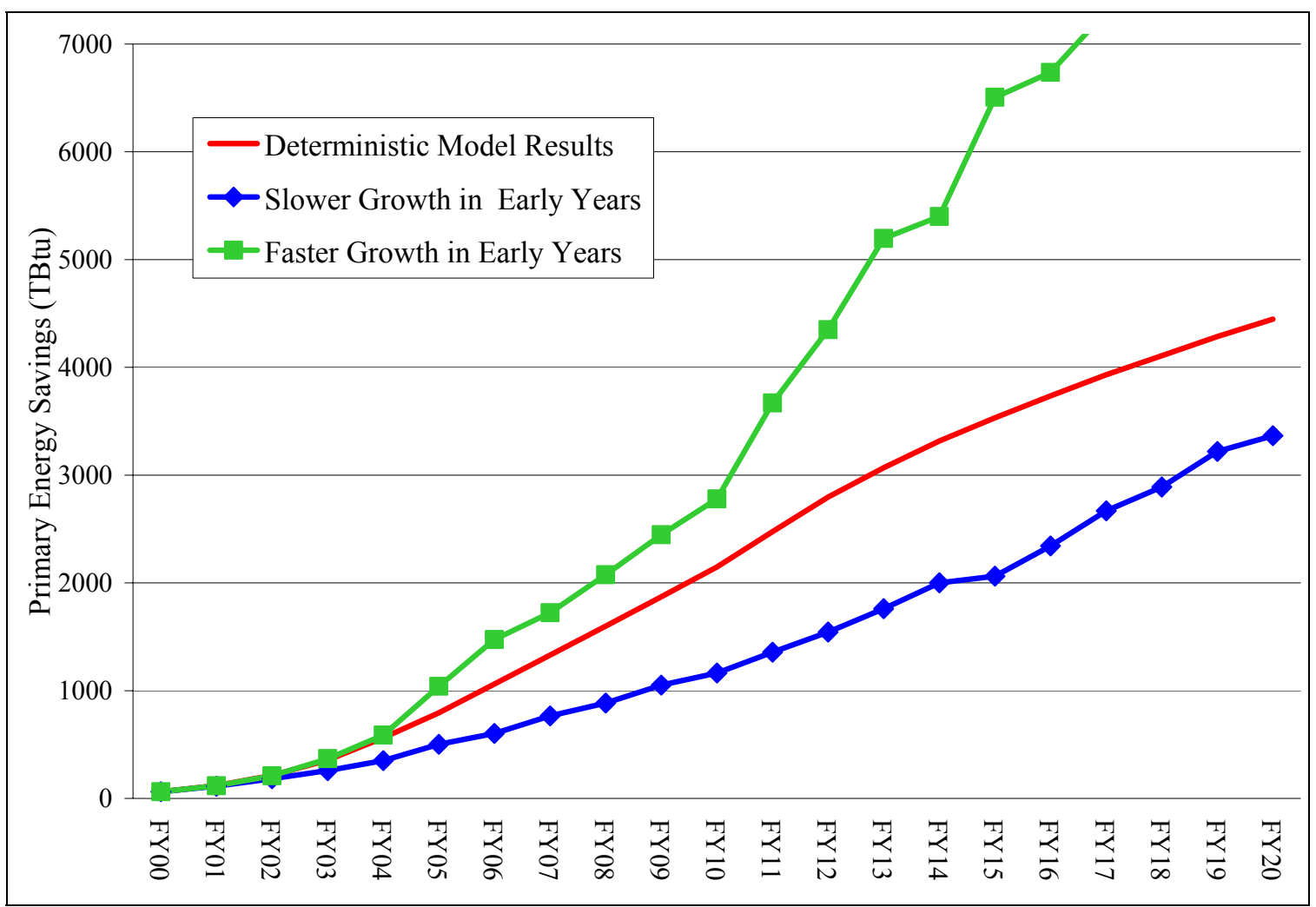

Figure 2.2. Actual Examples of Alternative Savings Trajectories Represented in the Risk Propagation Approach

Sixteen hypothetical normal distributions were modeled this way in a 20,000 observation Monte Carlo simulation. Table 2.2 details the specific probability distributions modeled for each risk level. For example, reasonable assumptions about low-risk program performance might lead to the selection of Case 15 from Table 2.2, where the average probability of success would be 95 percent with a standard deviation of 5 percent. In the risk propagation approach, this case could be used to capture an assumption that, in all likelihood, program managers generally would be satisfied with achieving 95 percent of an annual goal for their respective programs, while realizing that actual results could be significantly over (up to about 105 percent of) or under (below 85 percent of) that level. For the risk band approach, this case would result in a distribution of 2020 results that would range from less than 85 percent to more than 105 percent of the original GPRA point estimates for low-risk programs. Case 15 would apply a mean probability of 80 percent with a standard deviation of \pm 20 percent to medium-risk programs, and mean probability of 50 percent with a standard deviation of \pm 40 percent to high-risk programs. 
Table 2.2. Probability Scenarios Used to Simulate Risk Levels

\begin{tabular}{||c|c|c|c|c|c|c||}
\hline \multirow{2}{*}{ Risk Model } & \multicolumn{2}{|c|}{ Low Risk } & \multicolumn{2}{c|}{ Medium Risk } & \multicolumn{2}{c||}{ High Risk } \\
\cline { 2 - 7 } & Mean & Std. Dev. & Mean & Std. Dev. & Mean & Std. Dev. \\
\hline Case 1 & $85 \%$ & $20 \%$ & $60 \%$ & $50 \%$ & $25 \%$ & $70 \%$ \\
\hline Case 2 & $90 \%$ & $20 \%$ & $70 \%$ & $50 \%$ & $40 \%$ & $70 \%$ \\
\hline Case 3 & $95 \%$ & $20 \%$ & $80 \%$ & $50 \%$ & $50 \%$ & $70 \%$ \\
\hline Case 4 & $100 \%$ & $20 \%$ & $90 \%$ & $50 \%$ & $60 \%$ & $70 \%$ \\
\hline Case 5 & $85 \%$ & $15 \%$ & $60 \%$ & $40 \%$ & $25 \%$ & $60 \%$ \\
\hline Case 6 & $90 \%$ & $15 \%$ & $70 \%$ & $40 \%$ & $40 \%$ & $60 \%$ \\
\hline Case 7 & $95 \%$ & $15 \%$ & $80 \%$ & $40 \%$ & $50 \%$ & $60 \%$ \\
\hline Case 8 & $100 \%$ & $15 \%$ & $90 \%$ & $40 \%$ & $60 \%$ & $60 \%$ \\
\hline Case 9 & $85 \%$ & $10 \%$ & $60 \%$ & $30 \%$ & $25 \%$ & $50 \%$ \\
\hline Case 10 & $90 \%$ & $10 \%$ & $70 \%$ & $30 \%$ & $40 \%$ & $50 \%$ \\
\hline Case 11 & $95 \%$ & $10 \%$ & $80 \%$ & $30 \%$ & $50 \%$ & $50 \%$ \\
\hline Case 12 & $100 \%$ & $10 \%$ & $90 \%$ & $30 \%$ & $60 \%$ & $50 \%$ \\
\hline Case 13 & $85 \%$ & $5 \%$ & $60 \%$ & $20 \%$ & $25 \%$ & $40 \%$ \\
\hline Case 14 & $90 \%$ & $5 \%$ & $70 \%$ & $20 \%$ & $40 \%$ & $40 \%$ \\
\hline Case 15 & $95 \%$ & $5 \%$ & $80 \%$ & $20 \%$ & $50 \%$ & $40 \%$ \\
\hline Case 16 & $100 \%$ & $5 \%$ & $90 \%$ & $20 \%$ & $60 \%$ & $40 \%$ \\
\hline \hline
\end{tabular}

\subsection{Monte Carlo Simulation}

Monte Carlo simulation is the process of developing sample observations where none currently exist. If you assign a probability distribution to an outcome of a process, then simulate that process, say thousands of times, the result is a sample of potential outcomes that conforms to the distribution assigned. The mean of the sample would be the average probability of the estimated outcome under the assumptions employed.

The 16 cases developed to simulate low, medium, and high program-level risk of success were each simulated 20,000 times to populate the distribution of portfolio-level energy savings in 2020 under alternative risk levels. Both the risk band approach and the risk propagation approach were simulated this way. Again, the original FY2000 budget request GPRA estimates of primary energy savings seeded the simulation. Essentially, the simulation redraws the charts shown in Figure 2.3 and Figure 2.4 20,000 times for each risk case 


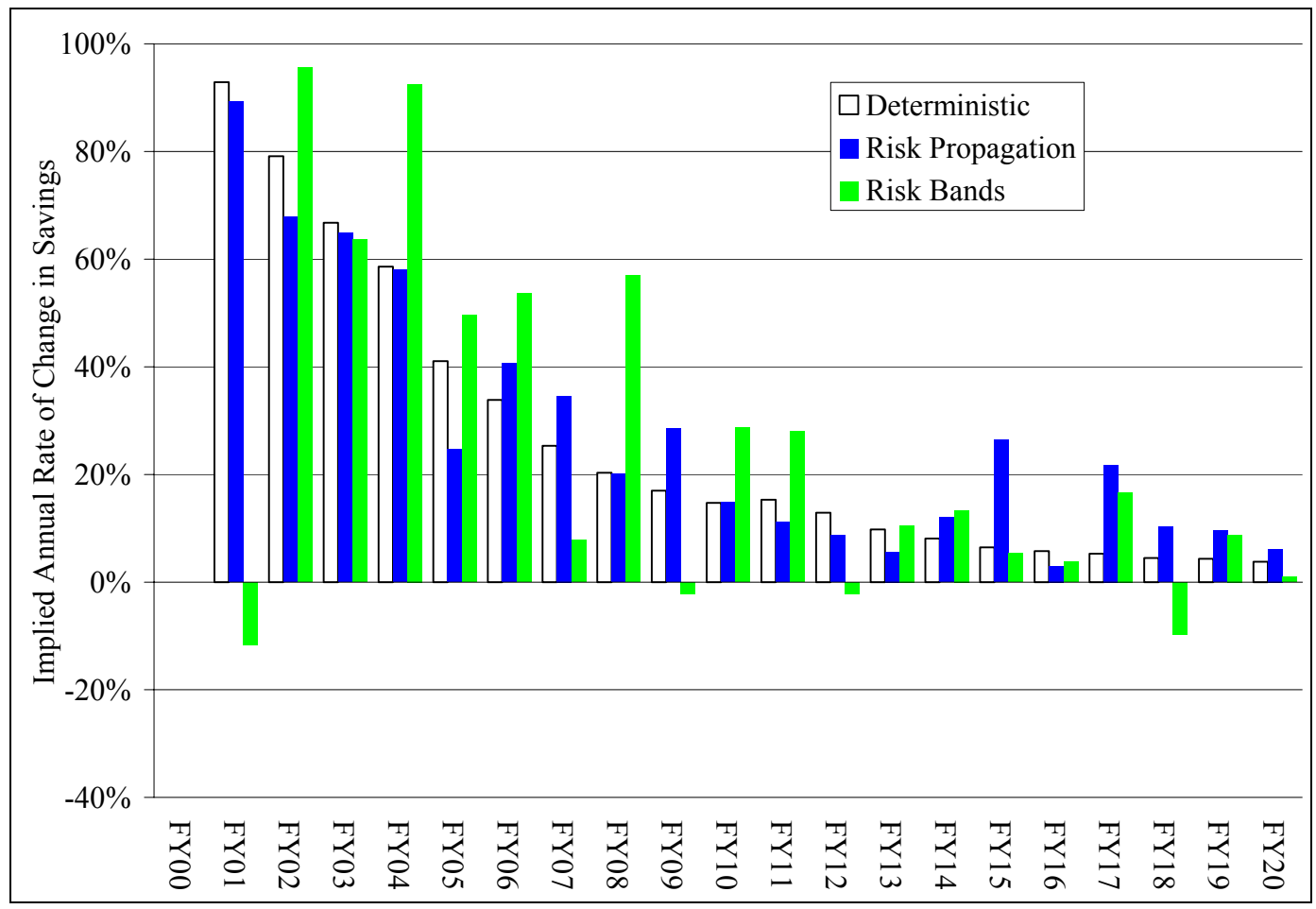

Figure 2.3. Example: Implied Annual Growth Rate Over Time for One Simulation Iteration

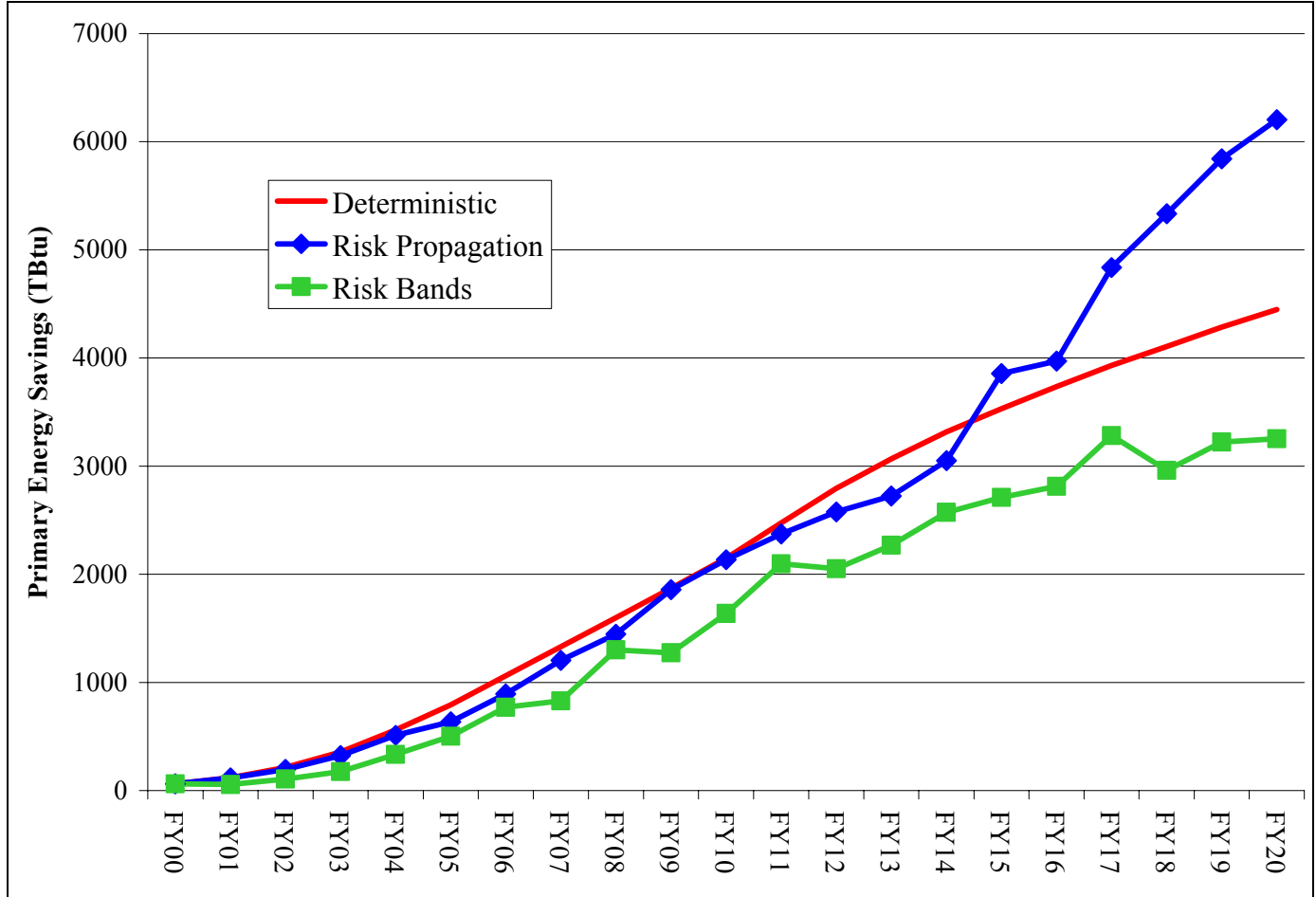

Figure 2.4. Example: Savings Streams from the Alternative Approaches for One Simulation Iteration 


\subsection{Results}

Results were produced for primary energy savings for the final year of estimates (2020) from the FY2000 budget request. The original deterministic analysis reported that the FY2000 budget request would result in about 4.4 quads of primary energy savings. Under the risk band approach, that figure ranges from over 2.5 quads to more than 3.6 quads, depending on the probability distributions modeled. Using risk propagation leads to the potential for estimated 2020 energy savings to vary between just over $1 / 2$ quad to almost 8 quads, depending on the risk assumption case modeled. Figure 3.1 presents these results graphically.

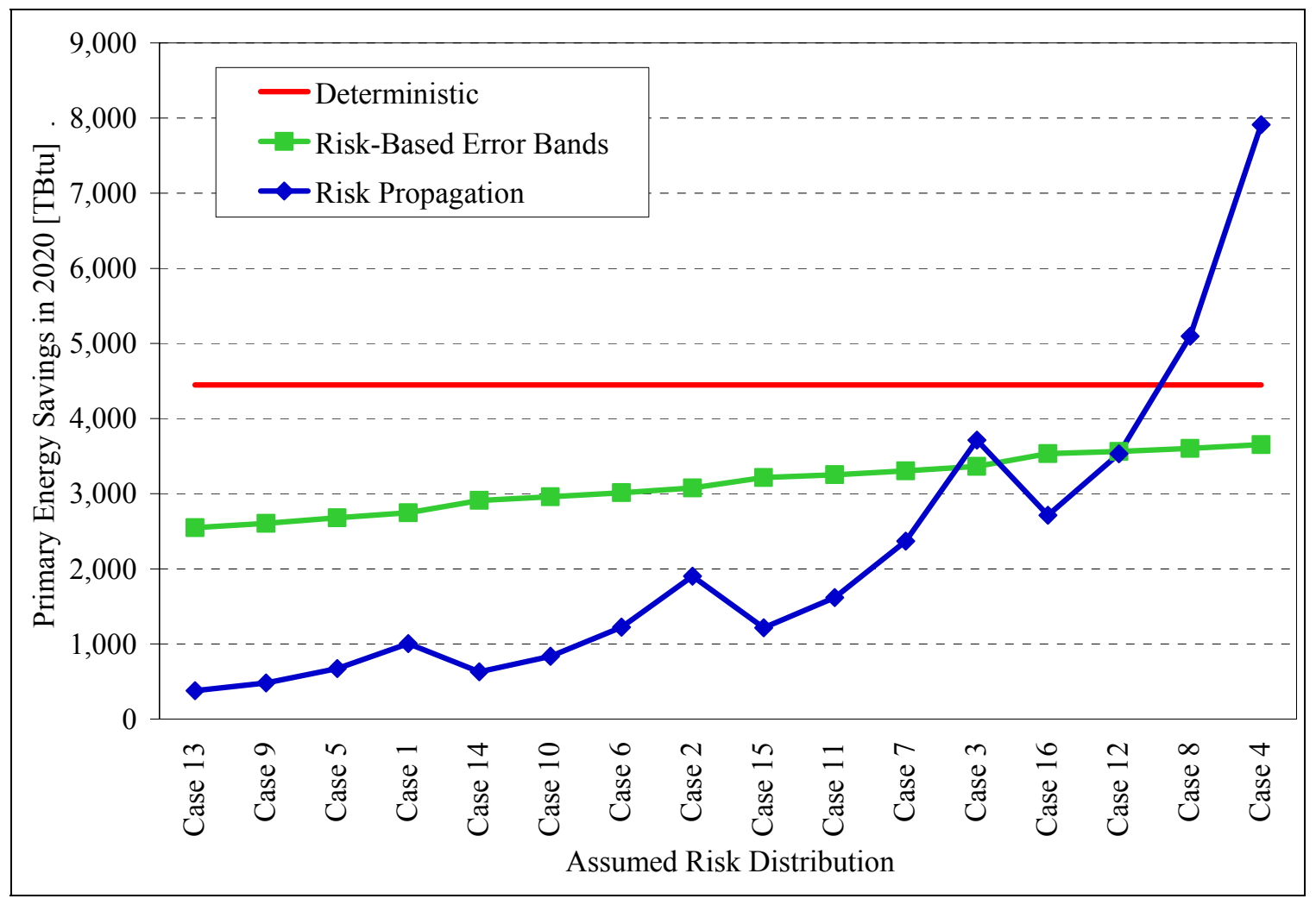

Figure 3.1. Simulation Means for 16 Year-2020 Energy Savings Distributions ( $n=20,000)$.

Each point in Figure 3.1 is the mean of the resulting distribution of energy savings results for each specific case modeled (see Table 2.2 for probability assignments to cases). As an example, Figure 3.2 looks at Case 12 in detail. Case 12 makes an interesting example only because by chance the two approaches to viewing risk closely converged in their estimates. Figure 6 illustrates the distribution of simulation results for Case 12 . In this case, low risk was assigned a mean probability of $100 \%$ chance of success with a standard deviation of 5\%; medium risk was assigned a mean probability of $90 \%$ chance of success with a standard deviation of $30 \%$; and high risk was assigned a mean probability of $60 \%$ chance of success with a standard deviation of $50 \%$. Figure 3.2 points out that each point charted in Figure 3.1 is really represented by a robust normal distribution generated by the simulation. 


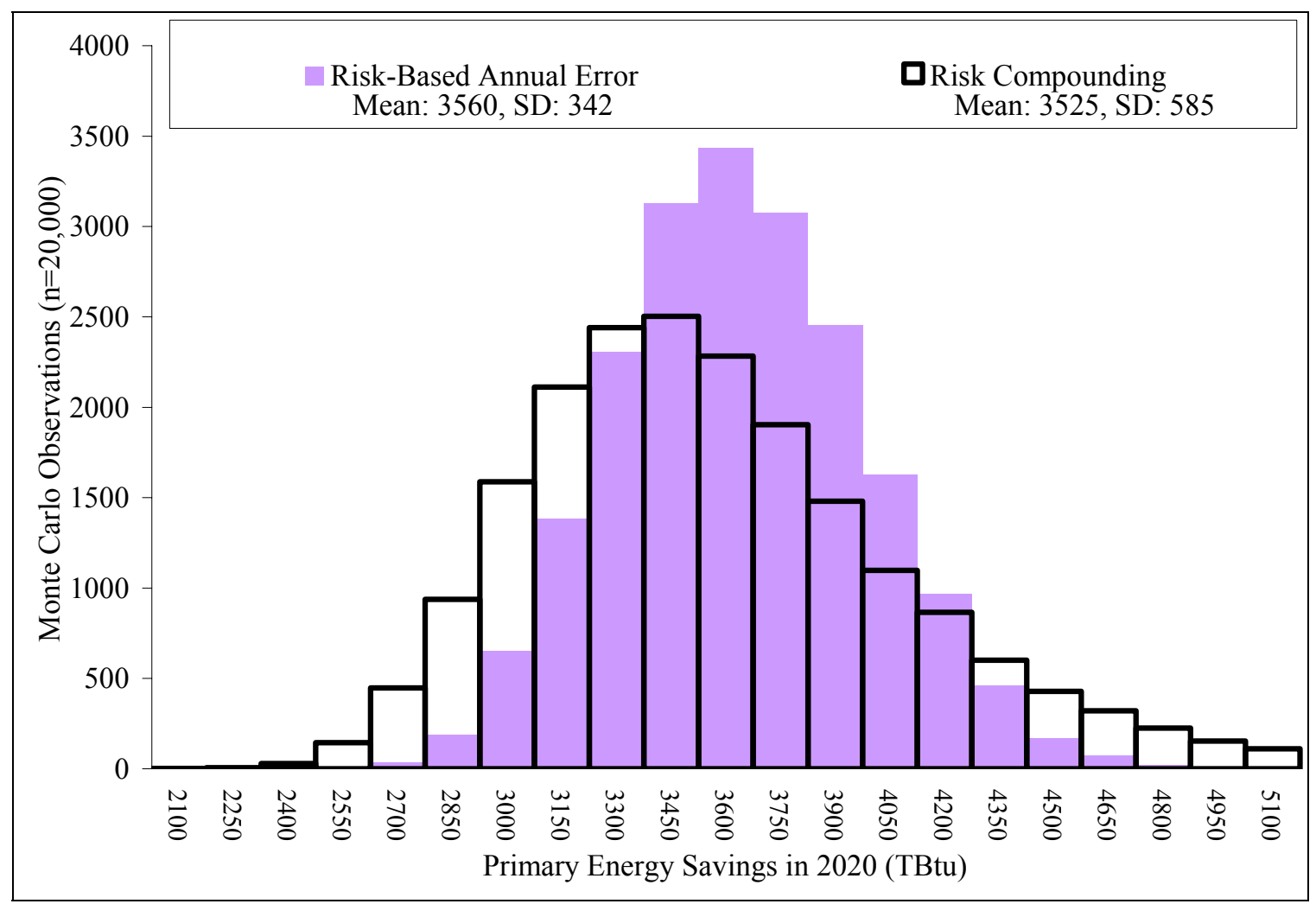

Figure 3.2. Distribution of 2020 Energy Savings Estimates Under Case 12

Table 3.1 provides the summary results for each of the cases simulated. Note that any of the 16 cases simulated might reflect a plausible outcome. However, continued work to refine the risk parameters with the state of knowledge at the program level is essential for any credibility to be assigned to such modeling approaches. 
Table 3.1. Estimated 2020 Portfolio Primary Energy Savings (TBtu) Distribution Statistics for the 16 Simulation Cases $(n=20,000)$

\begin{tabular}{||l|c|c|c|c||}
\hline \multirow{2}{*}{ Risk Model } & \multicolumn{2}{|c|}{ Risk Bands } & \multicolumn{2}{c|}{ Risk Propagation } \\
\cline { 2 - 5 } & Mean & SD & Mean & SD \\
\hline Case 1 & 2,752 & 407.1 & 1,007 & 250.0 \\
\hline Case 2 & 3,082 & 433.6 & 1,903 & 601.8 \\
\hline Case 3 & 3,361 & 448.4 & 3,721 & $1,450.4$ \\
\hline Case 4 & 3,653 & 471.3 & 7,883 & $3,623.3$ \\
\hline Case 5 & 2,679 & 350.0 & 670 & 106.6 \\
\hline Case 6 & 3,017 & 376.3 & 1,221 & 236.5 \\
\hline Case 7 & 3,300 & 391.8 & 2,372 & 554.4 \\
\hline Case 8 & 3,603 & 411.7 & 5,076 & $1,403.8$ \\
\hline Case 9 & 2,604 & 290.7 & 479 & 47.9 \\
\hline Case 10 & 2,958 & 315.7 & 837 & 98.4 \\
\hline Case 11 & 3,254 & 335.5 & 1,618 & 229.0 \\
\hline Case 12 & 3,560 & 342.4 & 3,525 & 585.1 \\
\hline Case 13 & 2,543 & 231.4 & 379 & 19.8 \\
\hline Case 14 & 2,906 & 259.4 & 631 & 38.9 \\
\hline Case 15 & 3,218 & 271.1 & 1,215 & 86.5 \\
\hline Case 16 & 3,533 & 278.1 & 2,712 & 224.6 \\
\hline \hline
\end{tabular}





\subsection{Discussion}

As developed originally, the 2020 point estimate for BTS portfolio energy savings for the FY2000 budget request was 4.447 quads. By its nature, that estimate does not account for the risk and uncertainty inherent in any multi-year program. Uncertainty or risk stems from the fact that, over 20-year planning horizons, things change. Even if budget funding were to remain stable over that period, as is to be assumed for the GPRA process, program outcomes are fraught with various forms of risk that may preclude outcomes from being achieved or may cause outcomes to greatly exceed original objectives.

The approach of simply adding risk bands to the annual deterministic energy savings estimates has the appeal of being generally intuitive and subject to less variation across probability distributions than the risk propagation approach. Under this approach, 2020 estimates would average 20 percent -40 percent lower than the deterministic estimates - given the risk cases used in this analysis. One potential pitfall of this approach is the lack of year-to-year dependency in the programs. Each year is treated independently, so a low savings estimate in one year does not have an effect on the next year's savings estimate. Implicit in this approach is the notion that savings in any one year could decline compared to a previous year. This generally goes against the idea that energy savings "lock-in".

The risk propagation approach subjects the estimates to year-to-year dependency. What happens in one year affects what can happen in the next year, but savings growth is constrained to not go negative for any year. This means that annual energy savings estimates will never decline compared to a previous year or once achieved, the savings lock-in. One principal pitfall of this approach is that it is not as intuitive as simply banding deterministic estimates. It involves assigning risk to the annual growth implied by the deterministic estimates. Another pitfall is the need to specify very tight probability distributions to the annual growth rate estimates. The compounding effect is very large for any significant changes in annual growth rates (departures from the implied rates of the deterministic approach) during the analysis horizon, which in this case lead to estimates that varied \pm 95 percent from deterministic estimates. The point could be argued that this approach might deal more realistically with the true risk facing the portfolio. 



\subsection{Conclusion}

Two approaches for introducing risk into annual portfolio energy savings estimates have been developed. To illustrate these approaches, 16 variants of risk assumption cases were developed and simulated. The individual programs making up the FY2000 BTS portfolio were subjectively assigned a risk level. There are many thousand additional permutations that could be gamed by varying program risk levels, changing probability distribution characteristics, or other combinations of changes. Expert opinion could be employed to assign risk levels to specific programs and to define appropriate characteristics for the probability distributions governing the results. The point is that producing annual energy savings estimates that reflect the appropriate amount of risk in each program can lead to more realistic program expectations and can make the program benefits more meaningful for planning processes.

All of these results serve to illustrate the significance of incorporating risk into the buildings portfolio analysis. Risk is important as it helps provide realism to the measurement of buildings programs. Accurate accounting for risk can prevent creation of false expectations for program success. It helps prevent the eventual disconnect between original savings forecasts and eventual savings measurement by minimizing that gap. Program-specific risk profiles vary widely and should be analyzed individually to assure accurate risk accounting through out the BT/WIP portfolio. 



\subsection{References}

Belzer, DB, KA Cort, JA Dirks, DJ Hostick, RH Pool. 2002. Documentation for FY 2003 BTS GPRA Metrics, PNNL-13845, Pacific Northwest National Laboratory, Richland, Washington. 


\section{Distribution}

No. of

\section{Copies}

\section{OFFSITE}

M. McCabe (3)

US Department of Energy

EERE-Building Technologies

EE-2J

1000 Independence Ave., S.W.

Washington DC 20585

J. D. Ryan

US Department of Energy

EERE-Building Technologies

EE-2J

1000 Independence Ave., S.W.

Washington DC 20585

J. Rannells

US Department of Energy

EERE-Building Technologies

EE-2J

1000 Independence Ave., S.W.

Washington DC 20585

E. Pollock

US Department of Energy

EERE-Building Technologies

EE-2J

1000 Independence Ave., S.W.

Washington DC 20585

B. Card

US Department of Energy

EERE-Building Technologies

EE-2J

1000 Independence Ave., S.W.

Washington DC 20585
No. of

\section{Copies}

R. Orrison

US Department of Energy

EERE-Building Technologies

EE-2J

1000 Independence Ave., S.W.

Washington DC 20585

Q. Laughlin

US Department of Energy

EERE-Building Technologies

EE-2J

1000 Independence Ave., S.W.

Washington DC 20585

B. Berringer

US Department of Energy

EERE-Building Technologies

EE-2J

1000 Independence Ave., S.W.

Washington DC 20585

J. Brodrick

US Department of Energy

EERE-Building Technologies

EE-2J

1000 Independence Ave., S.W.

Washington DC 20585

J. Millhone (3)

US Department of Energy

EERE-Weatherization and Intergovernmental

Program

EE-2K

1000 Independence Ave., S.W.

Washington DC 20585

Distr.1 
No. of

Copies

M. Bailey

US Department of Energy

EERE-Weatherization and Intergovernmental

Program

EE-2K

1000 Independence Ave., S.W.

Washington DC 20585

P. Hayes

US Department of Energy

EERE-Weatherization and Intergovernmental

Program

EE-2K

1000 Independence Ave., S.W.

Washington DC 20585

T. Heavey

US Department of Energy

EERE-Office of Planning, Budget

Formulation, and Analysis

EE-3B

1000 Independence Ave., S.W.

Washington DC 20585

M. B. Zimmerman

US Department of Energy

EERE-Office of Planning, Budget

Formulation, and Analysis

EE-3B

1000 Independence Ave., S.W.

Washington DC 20585

J. Dowd

US Department of Energy

EERE-Office of Planning, Budget

Formulation, and Analysis

EE-3B

1000 Independence Ave., S.W.

Washington DC 20585
No. of

Copies

P. Tseng

US Department of Energy

EERE-Office of Planning, Budget

Formulation, and Analysis

EE-3B

1000 Independence Ave., S.W.

Washington DC 20585

J. Dion (3)

US Department of Energy

EERE-Office of Planning, Budget

Formulation, and Analysis

EE-3B

1000 Independence Ave., S.W.

Washington DC 20585

K. Friedman

US Department of Energy

EERE-Office of Planning, Budget

Formulation, and Analysis

EE-3B

1000 Independence Ave., S.W.

Washington DC 20585

P. Podolak

US Department of Energy

EERE-Office of Planning, Budget

Formulation, and Analysis

EE-3B

1000 Independence Ave., S.W.

Washington DC 20585

P. Patterson

US Department of Energy

EERE-Office of Planning, Budget

Formulation, and Analysis

EE-3B

1000 Independence Ave., S.W.

Washington DC 20585

E. Barbour

Navigant Consulting

1801 K Street, NW

Suite 500

Washington, D.C. 20006

Distr.2 
No. of

Copies

ONSITE

DOE, Richland Operations Office

D.L. Biancosino K8-50

17 Pacific Northwest National Laboratory

D. M. Anderson (5) K6-05

D. B. Belzer K6-05

D. J. Hostick K6-05

K. A. Cort K6-05

J. A. Dirks K6-10

C. J. Hostick K8-23

E. M. Fathelramen K6-05

S. A. Shankle K5-16

T. M. Weber K6-01

Information Release Office (4) P8-55

$3 \quad$ Battelle Washington Office

S. C. McDonald (2) BWO

A. K. Nicholls BWO 